\title{
Maternal MTHFR interacts with the offspring's BCL3 genotypes, but not with TGFA, in increasing risk to nonsyndromic cleft lip with or without cleft palate
}

\author{
Dinamar A Gaspar ${ }^{1}$, Sergio R Matioli ${ }^{1}$, Rita de Cássia Pavanello ${ }^{1}$, Belmino C Araújo ${ }^{2}$, \\ Nivaldo Alonso ${ }^{3}$, Diego Wyszynski ${ }^{4}$ and Maria Rita Passos-Bueno*1
}

\author{
${ }^{1}$ Human Genome Center, Institute of Biosciences, University of São Paulo, São Paulo, Brazil; ${ }^{2}$ Hospital Menino Jesus, \\ São Paulo, Brazil; ${ }^{3}$ Department of Plastic Surgery, Faculty of Medicine, University of São Paulo, Brazil; ${ }^{4}$ Genetics \\ Program, Boston University School of Medicine, Boston, MA, US
}

The $677 \mathrm{C} \rightarrow \mathrm{T}$ polymorphism in the 5-10 methylenetetrahydrofolate reductase (MTHFR) gene has been associated with nonsyndromic cleft lip with or without cleft palate $(\mathrm{CL} / \mathrm{P})$ in some populations, but not others. Previous studies (ie, case-control and transmission disequilibrium tests (TDT)) in Brazilian families with $\mathrm{CL} / \mathrm{P}$ have been unable to replicate this putative association. However, our group observed a lower proportion of $C T$ heterozygotes among the mothers of $C L / P$ probands, suggesting that the maternal genotype for this polymorphism might influence predisposition to $\mathrm{CL} / \mathrm{P}$. In order to further examine this issue, we performed a case-control study of the $677 \mathrm{C} \rightarrow T$ /MTHFR polymorphism in families with $\mathrm{CL} / \mathrm{P}$ ascertained in two regions of Brazil: 172 from São Paulo (SP) and 252 from Ceará (CE). The control samples included 243 individuals from SP and 401 from CE. TDT was carried out in 102 patients with CL/P and their parents. No evidence of an association was observed between the $677 \mathrm{C} \rightarrow$ T/MTHFR polymorphism and $\mathrm{CL} / \mathrm{P}$ using the case-control design, while borderline significance was obtained with the TDT $(P=0.055)$. We have also looked for an interaction between maternal MTHFR genotypes and the propositi offspring's genotypes at two candidate susceptibility loci for CL/P, TGFA and BCL3. Interestingly, we observed an interaction between the maternal MTHFR and offspring's BCL3 genotypes (OR: $2.3 ; 95 \% \mathrm{Cl}: 1.1-4.8$; $P=0.03$ ) but not with the offspring's TGFA genotypes. Therefore, our results reinforce the idea that the maternal MTHFR genotype plays a significant role in susceptibility to $C L / P$, but its teratogenic effect depends on the genotype of the offspring.

European Journal of Human Genetics (2004) 12, 521-526. doi:10.1038/sj.ejhg.5201187

Published online 31 March 2004

Keywords: MTHFR; TGFA; BCL3; nonsyndromic cleft lip and/or palate

\section{Introduction}

Nonsyndromic cleft lip with or without cleft palate (CL/P) is a common malformation that affects approximately one

*Correspondence: MR Passos Bueno, Rua do Matão, 277, Departamento de Biologia, Instituto de Biociências, Universidade de São Paulo, São Paulo, Brazil. CEP: 05508-900, Tel: +55 113091 9910;

Fax: + 55113091 7419;

E-mail: passos@ib.usp.br.

Received 3 December 2003; revised 27 January 2004; accepted 11 February 2004 in every 600 newborn babies. ${ }^{1}$ The inheritance of $\mathrm{CL} / \mathrm{P}$ is complex and environmental and genetic factors are implicated in its occurrence. ${ }^{2-4}$

Deficiency of nutritional folic acid during embryonic development has been proposed as a candidate environmental factor in the etiology of CL/P, but the results of several studies are inconsistent. ${ }^{5-9}$ It has also been hypothesized that genetic variants in the enzymes controlling folate metabolism might play a role in the susceptibility of oral clefts. Two functional variants 
$(677 \mathrm{C} \rightarrow \mathrm{T}$ and $1298 \mathrm{~A} \rightarrow \mathrm{C})$ in the 5-10-methylenetetrahydrofolate reductase (MTHFR) gene have been widely studied. The $677 \mathrm{~T}$ allele is associated with a more thermolabile enzyme with reduced activity and TT homozygotes have a decrease of folate concentration in serum, plasma and red blood cells and a mild increase of plasma homocysteine concentrations. The $1298 \mathrm{C}$ allele also results in decreased MTHFR activity, but is not associated with higher homocysteine or lower plasma folate levels. Tolarova et $a l^{10}$ first observed that homozygotes for the $677 \mathrm{~T}$ allele were three times more frequent in CL/P Argentinean patients than in controls. However, these findings were not confirmed by most of the subsequent studies. ${ }^{11,12}$ In a previous study, we also did not observe evidence of an association between the $677 \mathrm{~T}$ allele and CL/P in patients. However, this polymorphism did not conform to HardyWeinberg $(\mathrm{H}-\mathrm{W})$ expectations among mothers of patients with $\mathrm{CL} / \mathrm{P}$ with a marginal level of significance $\left(\chi^{2}=4,3\right.$; $P<0.05)$. While this finding might be due to random chance, it could also suggest that the maternal genotype influences the predisposition to this malformation. ${ }^{13}$ An increased risk due to the maternal MTHFR genotype $(677 \mathrm{~T}$ or $1282 \mathrm{~A}$ alleles) on predisposition to $\mathrm{CL} / \mathrm{P}$ was suggested by others. ${ }^{14-17}$ Therefore, the role of MTHFR genotypes of patients or of mothers of affected individuals in the predisposition to oral clefts is still under discussion. In view of the importance of elucidating this issue, we analyzed the $677 \mathrm{C} \rightarrow \mathrm{T} / \mathrm{MTHFR}$ polymorphism through using the TDT and a case-control design in a large sample of Brazilian patients ascertained in different regions of Brazil (São Paulo (SP) and Ceará (CE)).

It is possible that the effect of some predisposing genes will be detected only when interaction between loci or with environmental factors are taken into account. Therefore, we also tested the hypothesis of an interaction between maternal MTHFR and CL/P offspring TGFA (transforming growth factor alpha) or BCL3 (B-cell leukemia/lymphoma-3) genotypes in the predisposition to nonsyndromic clefting. TGFA and BCL3 are known candidate susceptibility genes for CL/P; however, their effect on $\mathrm{CL} / \mathrm{P}$ risk remains controversial. ${ }^{4,18-22}$

\section{Patients and methods Families}

The sample studied comprised 424 families with at least one affected patient with CL/P: 172 from SP and 252 from CE. The SP families evaluated in our genetic counseling unit were referred to us from the plastic surgery clinics of the Hospital Menino Jesus and from the Hospital das Clínicas, School of Dentistry, University of São Paulo, SP, Brazil. The families from CE were ascertained through the Hospital Albert Sabin of Fortaleza during voluntary surgical missions of Operation Smile. All the patients were evaluated by at least one dysmorphologist who confirmed their nonsyndromic status. Familial history was investigated for each patient; $24 \%$ of cases (103/424) were classified as 'familial', that is, there was at least one 1st or 2nd degree affected relative. Study participants were classified as white and non-white (mulattoe and black) using a well-known subjective classification. ${ }^{23}$

A total of 644 control individuals were included in the analysis: 243 were relatives of patients with neuromuscular disorders (mean age: $34 \pm 10$ years) ascertained in our center at SP and 401 were healthy female subjects (mean age $29.6 \pm 9.8$ years) attending the Hospital Albert Sabin, $\mathrm{CE}$, for gynecologycal and obstetric routine. They had no family history of $\mathrm{CL} / \mathrm{P}$ and were matched to the cases and their mothers by socio-economic status and ethnic background.

All the individuals included in this research signed an informed consent in conformity with the regulations of the local Institutional Review Board.

\section{Genotyping of the $677 \mathrm{C} \rightarrow \mathrm{T}$ polymorphism in the MTHFR gene}

DNA was isolated from whole peripheral blood samples or buccal swabs according to standard techniques. ${ }^{24,25}$ The $677 \mathrm{C} \rightarrow \mathrm{T} / \mathrm{MTHFR}$ mutation was detected using standard protocols. ${ }^{26}$ All CT heterozygotes were also genotyped using the SNuPE test (Single Nucleotide Primer Extension), a semiautomatic method based on the primer extension assay and analyzed at Megabace (Amersham-Biosciences). The primer sequence used was 5'GCTGCGTGCTGATG AAATGC3'.

\section{Statistical analysis}

For association between the disease locus and the candidate gene, the data were analyzed using the $\chi^{2}$-test and TDT. $^{27} \mathrm{H}-\mathrm{W}$ equilibrium was tested according to the method of Guo and Thompson ${ }^{28}$ and performed with the help of the Arlequin software. ${ }^{29}$

We tested for the hypothesis of interaction between the maternal 677T/MTHFR allele and the CL/P offspring C2/ TaqI allele at the TGFA locus $(N=274)$ or the $\mathrm{CL} / \mathrm{P}$ offspring $135 \mathrm{bp}$ allele of the intragenic marker in the BCL3 gene $(N=292)$. We also tested for interactions between the $677 \mathrm{~T} / \mathrm{MTHFR}$ allele and the C2/TaqI-TGFA or $135 \mathrm{bp} / \mathrm{BCL} 3$ alleles in mothers of CL/P patients and among the affected individuals. Some of the BCL3 and TGFA data have already been included in previous reports. $^{20,22}$

Gene-gene interactions were tested using a two-step approach. First, we applied a linkage disequilibrium test to verify if a combination of alleles at two different loci is preferentially present in the considered sample. The tested markers were located in different chromosomes; thus, any significant result would be due to an increased combination of genotypes in the tested samples and not to genetic linkage. The tests were performed according to the method 
proposed by Slatkin and Excoffier ${ }^{30}$ with the help of the Arlequin software. ${ }^{29}$ This method uses information of genotypic data from two loci in the absence of information on the gametic phase of alleles, assuming $\mathrm{H}-\mathrm{W}$ equilibrium. In the second step, to identify the high-risk alleles for both loci, we performed the case-only method described by Yang et $a l^{31}$ for four possible combinations, where $\mathrm{x}$ in the BCL3 locus stands for any allele other than the $135 \mathrm{bp}$ allele, according to the different schemes of dominance: (a) maternal 677C/MTHFR allele and offspring's $135 \mathrm{bp} / \mathrm{BCL} 3$ allele; (b) maternal 677C/MTHFR allele and offspring x/BCL3 allele; (c) maternal 677T/ MTHFR allele and offspring $135 \mathrm{bp} / \mathrm{BCL} 3$ allele; (d) maternal 677T/MTHFR allele and offspring x/BCL3 allele. Under the assumption of independent gene frequencies in the population, the case-only design provides an estimate of the ratio of the joint effect divided by the product of the individual effects of each gene alone, which can be regarded as effect measure modification of risk ratio on a multiplicative scale or a gene-gene interaction of the risk ratio.

The level of significance adopted for all analysis was 0.05 .

\section{Results}

$677 \mathrm{C} \rightarrow \mathrm{T}$ allele prevalence by geographic region and racial group

The genotypic frequencies of all groups were in $\mathrm{H}-\mathrm{W}$ equilibrium and did not differ between each of the groups ascertained in the two different regions of Brazil (data available upon request). Therefore we merged each cate- gory ascertained in SP and CE respectively into three groups (patients, $n=424$; mothers of $\mathrm{CL} / \mathrm{P}$ patients, $n=336$; and controls, $n=644$; Table 1 ) in both the casecontrol and the TDT analyses.

We observed a similar proportion of white and nonwhite in all the sample groups (Table 1) and no statistical difference in the TT genotype frequency (or allele 677 T frequency) was observed between white and nonwhite in each of the three groups (Table 1). Therefore, ethnicity was not used in any further analysis.

\section{Association studies between $677 \mathrm{C} \rightarrow \mathrm{T} / \mathrm{MTHFR}$ polymorphism and $\mathrm{CL} / \mathrm{P}$}

We did not observe a significant difference of the $677 \mathrm{~T}$ allele or TT genotype frequencies between the CL/P patients and controls $\left(\chi^{2}=1.47 ; 2 \mathrm{df} ; P=0.48\right)$. Gender, type of cleft and number of affected individuals in the family did not influence the results (data not shown). TDT analysis was carried out in 102 trios, but only 62 were informative. Marginally significant evidence of excess transmission of the $\mathrm{T}$ allele at MTHFR was observed $\left(\chi^{2}=3.75,1 \mathrm{df} ; P=0.055\right)$.

\section{Gene-gene interactions}

We did not find any evidence of interaction between maternal MTHFR genotype and offspring's TGFA genotype (exact $P=0.86$ ); however, evidence of dependence with a borderline level of significance was observed between maternal MTHFR genotypes and offspring BCL3 genotypes (exact $P=0.05$ ). This effect was also observed through the case-only method. As shown in Table 2, the most significant result of allelic grouping of genotypes was obtained when the presence of the maternal $677 \mathrm{~T}$ allele of

Table 1 Genotypes and allelic distribution of $677 \mathrm{C} \rightarrow$ T/MTHFR polymorphism in patients, their mothers and controls

\begin{tabular}{|c|c|c|c|c|c|c|c|c|}
\hline \multirow{2}{*}{ Categories } & \multirow{2}{*}{ Ethnic group } & \multicolumn{3}{|c|}{ Genotypes N (\%) } & \multirow{2}{*}{$N$} & \multicolumn{2}{|c|}{ Allelic frequencies } & \multirow{2}{*}{$H-W^{a}$} \\
\hline & & CC & $C T$ & $T T$ & & $C$ & $T$ & \\
\hline \multirow[t]{2}{*}{ Patients } & $\begin{array}{l}\text { Whites } \\
\text { Nonwhites } \\
\text { Unclassified }\end{array}$ & $\begin{array}{r}168(49.5) \\
39(58.2) \\
6(35.3)\end{array}$ & $\begin{array}{r}140(41) \\
23(34.3) \\
9(52.9)\end{array}$ & $\begin{array}{c}32(9.5) \\
5(7.5) \\
2(11.8)\end{array}$ & $\begin{array}{c}340 \\
67 \\
17\end{array}$ & & & \\
\hline & Total & $213(50.2)$ & $172(40.6)$ & $39(9.2)$ & 424 & 0.71 & 0.29 & $\chi^{2}=0.25 ; 1 \mathrm{df} ; P=0.61$ \\
\hline \multirow[t]{2}{*}{ Mothers } & $\begin{array}{l}\text { Whites } \\
\text { Nonwhites } \\
\text { Unclassified }\end{array}$ & $\begin{array}{r}126(53.6) \\
40(51.9) \\
8(33.3)\end{array}$ & $\begin{array}{l}88(37.4) \\
31(40.3) \\
12(50.0)\end{array}$ & $\begin{array}{c}21(9.0) \\
6(7.8) \\
4(16.7)\end{array}$ & $\begin{array}{l}235 \\
77 \\
24\end{array}$ & & & \\
\hline & Total & $174(51.8)$ & $131(39.0)$ & $31(9.2)$ & 336 & 0.71 & 0.29 & $\chi^{2}=0.77 ; 1 \mathrm{df} ; P=0.38$ \\
\hline \multirow[t]{2}{*}{ Controls } & $\begin{array}{l}\text { Whites } \\
\text { Nonwhites } \\
\text { Unclassified }\end{array}$ & $\begin{array}{r}235(49.6) \\
43(47.8) \\
49(61.3)\end{array}$ & $\begin{array}{r}202(42.6) \\
39(43.3) \\
28(35.0)\end{array}$ & $\begin{array}{r}37(7.8) \\
8(8.9) \\
3(3.7)\end{array}$ & $\begin{array}{c}474 \\
90 \\
80\end{array}$ & & & \\
\hline & Total & $327(50.8)$ & $269(41.8)$ & $48(7.4)$ & 644 & 0.72 & 0.28 & $\chi^{2}=0.52 ; 1 \mathrm{df} ; P=0.47$ \\
\hline
\end{tabular}

${ }^{\mathrm{a}} \mathrm{H}-\mathrm{W}=$ Hardy-Weinberg; Comparison between whites and non-whites; Controls: $\chi^{2}=0.17 ; 2 \mathrm{df} ; P=0.92 ;$ patients: $\chi^{2}=1.74 ; 2 \mathrm{df} ; P=0.42 ;$ mothers of $\mathrm{CL} / \mathrm{P}$ patients: $\chi^{2}=0.24 ; 2 \mathrm{df} ; P=0.89$. 
Table 2 Maternal MTHFR and offspring BCL3 genotypes

\begin{tabular}{lccc}
\hline \multirow{2}{*}{ Maternal MTHFR genotype } & \multicolumn{3}{c}{ Offspring BCL3 genotypes $^{a}$} \\
\cline { 2 - 4 } & $135 b p / 135 b p$ & $135 b p / x$ & $x / x$ \\
\hline CC & 74 & 63 & 12 \\
CT & 44 & 51 & 13 \\
TT & 13 & 11 & 5 \\
Total & 149 & 114 & 29 \\
Maternal MTHFR genotype & Offspring genotypes & & \\
\cline { 2 - 3 } & \multicolumn{2}{c}{135 bp/x } & \multicolumn{2}{c}{$x / x$} \\
\hline CC & $137(91.9 \%)$ & $12(8 \%)$ \\
CT+TT & $119(83 \%)$ & $24(16 \%)$ \\
\hline
\end{tabular}

We are showing the raw data and the grouping that showed a significative interaction between maternal MTHFR and offspring's BCL3 genotype.

${ }^{a}$ The BCL3 genotypes were merged in three classes $(135 \mathrm{bp} / 135 \mathrm{bpb}$, $135 \mathrm{bp} / \mathrm{x}$ and $\mathrm{x} / \mathrm{x}$ ) where $135 \mathrm{bp}$ denotes the allele most frequent and $x$ denotes, any other allele at the BCL3 locus. For odds ratio estimates, four groupings were performed: (a) maternal 677C/MTHFR allele and offspring's $135 \mathrm{bp} / \mathrm{BCL} 3$ allele; (b) maternal 677C/MTHFR allele and offsprings $\mathrm{x} / \mathrm{BCL} 3$ allele; (c) maternal $677 \mathrm{~T} / \mathrm{MTHFR}$ allele and offsprings $135 \mathrm{bp} / \mathrm{BCL} 3$ allele; (d) maternal 677T/MTHFR allele and offsprings $\mathrm{x} / \mathrm{BCL} 3$ allele.

${ }^{b}$ OR: $2.3 ; 95 \% \mathrm{Cl}: 1.1-4.8 ; P=0.03$.

MTHFR locus was assessed with the offspring non $135 \mathrm{bp} /$ BCL3 alleles (odds ratio $(\mathrm{OR})=2.3, P=0.03,95 \% \mathrm{CI}=1.1$ 4.8; Table 2). No evidence of interaction was observed between MTHFR and TGFA in mothers of CL/P patients ( $n=77$; exact $P=1.0)$ or in affected propositi $(n=263$; exact $P=0.65)$. A similar search for interaction among MTHFR and BCL3 genotypes among 274 children (exact $P=0.85$ ) and 82 mothers (exact $P=0.42$ ) yielded no statistically significant evidence of association.

\section{Discussion}

$677 \mathrm{C} \rightarrow \mathrm{T}$ allele prevalence in controls from SP and CE The ethnic origin of the Brazilian population is highly heterogeneous with three major components: Latin-European whites, Afro-Brazilian blacks and Amerindians. The prevalence of homozygotes for the allele 677T/MTHFR is higher among nonmixed white people (10\%) and considerably lower among black persons (1.45\%) and Amerindian Brazilian groups (1.2\%). ${ }^{32,33}$ The similar frequency of the TT genotype (or $677 \mathrm{~T}$ allele) between white and nonwhite observed in the present study should reflect the large racial admixture of the Brazilian population, as reported by others who also studied a mixed Brazilian population. ${ }^{34}$

Genetic selection associated with the TT MTHFR genotype, including a decreased viability in utero for female $677 \mathrm{~T}$ homozygote fetuses, has been suggested by some authors. $^{35}$ The finding that all samples are in $\mathrm{H}-\mathrm{W}$ equilibrium together with the observation that the percentage of female CL/P cases did not differ by MTHFR genotype (data not shown) do not support selection of TT genotype in our samples.

\section{$677 \mathrm{C} \rightarrow \mathrm{T} / \mathrm{MTHFR}$ polymorphism as a susceptibility factor for $\mathrm{CL} / \mathrm{P}$}

Our case-control study and TDT results suggest that the 677T/MTHFR allele alone does not have a strong genetic effect on cleft susceptibility at the at-risk embryo. This is in agreement with most of the published literature, including our previous report. ${ }^{11-17,36}$

The MTHFR maternal genotype distribution observed in the present study is comparable to that in controls and it is in $\mathrm{H}-\mathrm{W}$ equilibrium, suggesting that the slight deviation of $\mathrm{H}-\mathrm{W}$ in mothers of $\mathrm{CL} / \mathrm{P}$ offspring previously reported by us is likely to be a spurious result. Martinelli et al ${ }^{14}$ observed a significantly higher frequency of the mutant $\mathrm{T}$ allele in mothers of CL/P as compared to controls, while others observed this distortion only when the families were subdivided by parental affection status ${ }^{15}$ or when haplotypes at the MTHFR locus were analysed ${ }^{37}$ or if the mothers had a low periconceptional folate intake. ${ }^{17}$ Still others, found that mothers carrying either one or two copies of the $677 \mathrm{C} \rightarrow \mathrm{T}$ variant presented a reduced risk to $\mathrm{CL} / \mathrm{P}$ in the child in a dose-dependent manner. ${ }^{16}$ In summary, the contribution of the maternal MTHFR genotype to predisposition of the orofacial cleft is still controversial; however, the majority of the studies agree that the developing embryo's MTHFR genotype has little contribution to the risk of this malformation.

\section{Gene-gene interactions}

It is possible that the effect of some predisposing genes will be observed only if analyzed in conjunction with other loci or with environmental factors. We can consider the maternal genotype as an environmental factor, whose effect would be indeed an increase or decrease of substances that can act in embryo development. Taking this into account, the analysis of the effect of maternal genes is of particular interest, particularly those that metabolize essential nutrients, which might play an important role during early stages of the developing embryo. In the present study, we investigated the possible interaction of the maternal MTHFR genotype with TGFA or BCL3 genotypes of their offspring with CL/P.

Ardinger et al $^{18}$ first reported an association between the rare allele of TaqI/C2 RFLP (restriction fragment polymorphism) at the TGFA locus and CL/P in a case-control study. These findings were replicated in some studies, but there have been a growing number of reports not confirming this association (revised in). ${ }^{4,22}$ Considering that deficiency of folate would cause an impairment on cell proliferation or migration during embryogenesis, we hypothesized that the presence of a maternal CT or TT/ 
MTHFR genotype together with the embryo C1C2/TGFA or C2C2/TGFA genotypes may favor the occurrence of CL/P. We did not observe any interaction between maternal MTHFR and TGFA offspring genotypes. Therefore, our data further confirm that TGFA is not an important susceptibility or modifier locus for orofacial clefts, at least in our population.

BCL3, a proto-oncogene at 19q13 that encodes a member of the IkB protein family of inhibitors of NF-kB that might be involved with cell proliferation, differentiation and apoptosis, ${ }^{38,42}$ has been considered a susceptibility locus for CL/P. ${ }^{19,20,39-41}$ In most of the association studies, it has been observed that the $135 \mathrm{bp} / \mathrm{BCL} 3$ allele segregates more often to CL/P offspring than the other alleles. Because the $135 \mathrm{bp}$ allele is, by far, the most frequent allele in all the populations studied to date, it is very likely that the associations reported of $\mathrm{CL} / \mathrm{P}$ with this allele are mainly due to its high frequency and not to a causal effect. As we have suggested earlier, ${ }^{20}$ multiple predisposing mutations may exist close to or within the BCL3 locus, because a specific haplotype with markers of this region in significant linkage disequilibrium with $\mathrm{CL} / \mathrm{P}$ has not been found.

The case-only analysis in Table 2 suggests a possible interaction between maternal MTHFR genotypes and the child's BCL3 genotype. Significant disequilibrium between the two loci may also be the result of populational admixture. However, this effect would also be produced when the loci were analyzed in people of the same generation. Once we have only observed disequilibrium between the maternal MTHFR genotype and the propositus genotype of BCL3, the hypothesis of an admixture effect can be discarded.

The pathogenic mechanism by which a decrease in folate exerts its detrimental effect is not well understood. Folate is of fundamental importance in the synthesis of purines and pyrimidines, which are the basic compounds of DNA and tRNA. Therefore, a folate deficiency will easily influence cell multiplication processes. On the other hand, homocysteine is the demethylated derivative of methionine, which is, after conversion to S-adenosylmethionine, the most important methyl group donor in the body. Hypomethylation can change the transcriptional level of some genes that might interefere in the cleft and lip morphogenesis. ${ }^{43}$ Less functional MTHFR in the mother will lead to an increase of homocysteine plasma maternal level, which can enter the amniotic fluid of the developing fetus at levels correlating with those of their mothers. In these cases, high homocysteine levels in the embryo may disrupt the normal palate development, which might be through apoptosis induced by oxidative stress. ${ }^{43,44}$ Therefore, based on the data reported here, it is reasonable to speculate that slightly higher maternal homocysteine levels might be teratogenic possibly depending on the fetus genotype and fetal BCL3 gene expression might be regulated by the homocysteine metabolic pathway.
In conclusion, this study points to the importance of the maternal MTHFR genotype on the predisposition to this malformation. In addition, the effect of the maternal MTHFR genotype depends on the embryo genotype at other loci, as expected in a multifactorial inheritance. It would be important to review the strategies used to identify the loci predisposing for oral clefts or other malformations with complex inheritance as well as to better investigate the possible biochemical relationship between homocysteine metabolism and BCL3 gene expression. In order to validate our findings, it is also important to verify the expression pattern of BCL3, MTHFR during the early stages of embryonic development.

\section{Acknowledgements}

We thank all of the patients and their relatives; Andréa Sertié for reading the manuscript; Carlos Maranduba for help on the analysis of the SNUPE; Constância G Urbani for secretarial help; Faculty of Dentistry at University of São Paulo, Association of Orofacial Clefts of Concórdia, Santa Catarina, and Hospital Albert Sabin, Ceará, Brazil for referring some patients. This work was supported by grants from FAPESP/CEPID, PRONEX, CNPq (except DFW). Part of this work was funded by a contract from the Massachusetts Center for Birth Defects Research and Prevention of the Massachusetts Department of Public Health (to DFW) and by an Etiology Grant of the Cleft Palate Foundation (to DFW).

\section{References}

1 Mossey PA, Little J: Epidemiology of oral clefts: an international perspective; in Wyszynski DF (ed): Cleft lip and palate: From origin to treatment. New York: Oxford University Press; 2002, pp 127-158.

2 Wyszynski DF, Beaty TH, Maestri NE: Genetics of nonsyndromic oral clefts revisited. Cleft Palate Craniofac J 1996; 33: 406-417.

3 Gorlin RJ, Cohen Jr MM, Levin LS: Syndrome of the head and neck. New York: Oxford University Press; 2001, 4th edn. pp 850-859.

4 Murray JC: Gene/environment causes of cleft lip and/or palate. Clin Genet 2002; 61: 248-256.

5 Khoury MJ, Gomez-Farial M, Mulinare J: Does maternal cigarette smoking during pregnancy cause cleft lip and palate in offspring? Am J Dis Child 1989; 143: 333-337.

6 Shaw GM, Lammer EJ, Wasserman CR, O'Malley CD, Tolarova MM: Risks of orofacial clefts in children born to women using multivitamins containing folic acid periconceptionally. Lancet 1995; 354: 393-396.

7 Czeizel AE, Toth M, Rockenbauer M: Population based casecontrol study of folic acid supplementation during pregnancy. Teratology 1996; 53: 345-351.

8 Itikala PR, Waltkins ML, Mulinare J, Moore CA, Liu Y: Maternal multivitamin use and orofacial clefts in offspring. Teratology 2001; 63: 79-86.

9 Czeizel AE: Prevention of oral clefts through the use of folic acid and multivitamin supplements: evidence and gaps; in Wyszynski DF (ed): Cleft lip and palate: From origin to treatment. New York: Oxford University Press; 2002, pp 443-457.

10 Tolarova MM, Van Rooij M, Pastor M et al: A common mutation in the MTHFR gene is a risk factor for nonsyndromic cleft lip and palate anomalies. Am J Hum Genet 1998; 63: A27.

11 Shaw GM, Rozen R, Finnell RH, Todoroff K, Lammer EJ: Infant C677T mutation in MTHFR, maternal periconceptional vitamin use and cleft lip. Am J Med Genet 1998; 80: 196-198. 
12 Mills JL, Kirke PN, Molloy AM et al: Methylenetetrahydrofolate reductase thermolabile variant and oral clefts. Am J Med Genet 1999; 86: 71-74.

13 Gaspar DA, Pavanello RC, Zatz $\mathrm{M}$ et al: Role of the C677T polymorphism at the MTHFR gene on risk to nonsyndromic cleft lip with/without cleft palate: results from a case-control study in Brazil. Am J Med Genet 1999; 87: 197-199.

14 Martinelli M, Scapoli L, Pezzetti F et al: Linkage analysis of the three candidate regions of chromosome 1 in nonsyndromic familial orofacial cleft. Ann Hum Genet 2001; 65: 465-471.

15 Prescott NJ, Winter RM, Malcolm S: Maternal MTHFR genotype contributes to the risk of nonsyndromic cleft lip and palate. J Med Genet 2002; 39: 368-369.

16 Jugessur A, Wilcox AJ, Lie RT et al: Exploring the effects of methylenetetrahydrofolate reductase gene variants C677T and A1298C on the risk of orofacial clefts in 261 Norwegian caseparent triads. Am J Epidemol 2003; 157: 1083-1091.

17 van Rooij IALM, Vermeij-Keers C, Kluijtmans LAJ et al: Does the interaction between maternal folate intake and the methylenetetrahydrofolate reductase polymorphisms affect the risk of cleft lip with or without cleft palate? Am J Epidemiol 2003; 157: 583-591.

18 Ardinger HH, Buetow KH, Bell GI, Bardach J, Van-Demark DR, Murray JC: Association of genetic variation of the transforming growth factor-alpha gene with cleft lip and palate. Am J Hum Genet 1989; 45: 348-353.

19 Stein J, Mulliken JB, Stal S et al: Nonsyndromic cleft lip with or without cleft palate: evidencce of linkage to BCL3 in 17 multigenerational families. Am J Hum Genet 1995; 57: 257-272.

20 Gaspar DA, Matiolli S, Pavanello RC et al: Evidence that BCL3 plays a role in the etiology of nonsyndromic oral clefts in Brazilian families. Genet Epidemiol 2002; 23: 364-374.

21 Wyszynski DF: Locating genes for oral clefts in humans; In Wyszynski DF (ed): Cleft lip and palate: From origin to treatment. New York: Oxford University Press; 2002, pp 255-264.

22 Passos-Bueno MR, Gaspar DA, Kamiya T et al: Transforming growth factor alpha (TGFA) and nonsyndromic cleft lip with or without palate $(\mathrm{CL} / \mathrm{P})$ in Brazilian patients: results of a large casecontrol study. Cleft Palate J 2004, in press.

23 Azevedo ES: Subgroup studies of black admixture within a mixed population of Bahia, Brazil. Ann Hum Genet 1980; 44: 56-60.

24 Miller AS, Dykes DD, Polesky HF: A simple salting out procedure for extracting DNA from human nucleated cells. Nucleic Acids Res 1988; 16: 1215.

25 Richards B, Skolesky J, Shuber AP et al: Multiplex PCR amplification from the CFTR gene using DNA prepared from buccal brushes/ swabs. Hum Mol Genet 1993; 2: 159-163.

26 Frosst P, Blom HJ, Milos R et al: A candidate genetic risk factor for vascular disease: a common mutation in methylenetetrahydrofolate reductase. Nat Genet 1995; 10: 111-113.

27 Spielman RS, MacGinnis RE, Ewens WJ: Transmission test for linkage disequilibrium: the insulin gene region and insulindependent diabetes mellitus (IDDM). Am J Hum Genet 1993; 52: $506-516$.

28 Guo S, Thompson E: Performing the exact test of HardyWeinberg proportion for multiple alleles. Biometrics 1992; 48: $361-372$.
29 Schneider S, Roessli D, Excoffier L: Arlequin 2.00, a software for population genetics data analyses. Geneva: Department of Anthropology and Ecology, University of Geneva; 2001.

30 Slatkin M, Excoffier L: Testing for linkage disequilibrium in genotypic data using the EM algorithm. Heredity 1996; 76: $377-383$.

31 Yang Q, Khoury MJ, Sun F, Flanders WD: Case-only design to measure gene-gene interaction. Epidemiology 1999; 10: 167-170.

32 Arruda VR, Siqueira LH, Gonçalves MS et al: Prevalence of the mutation C677T in the methylenetetrahydrofolate reductase gene among distinct ethnic groups in Brazil. Am J Med Genet 1998; 78: 332-335.

33 Franco RF, Araújo AG, Guerreiro JF, Elion J, Zago M: Analysis of the C677T mutation of the methylenetetrahydrofolate reductase gene in different ethnic groups. Thromb Haemost 1998; 79: 119-121.

34 Perez ABA, DAlmeida V, Vergani N, Oliveira AC, Lima FT, Brunoni D: Methylenetetrahydrofolate reductase (MTHFR): Incidence of mutations C677T and A1298C in Brazilian population and its correlation with plasma homocysteine levels in spina bifida. Am J Med Genet 2003; 119A: 20-25.

35 Rozen R, Fraser FC, Shaw G: Decreased proportion of female newborn infants homozygous for the $677 \mathrm{C} \rightarrow \mathrm{T}$ mutation in methylenetetrahydrofolate reductase. Am J Med Genet 1999; 83: $142-143$.

36 Beaty TH, Hetmanski JS, Zeiger JS et al: Testing candidate genes for nonsyndromic oral clefts using a case-parent trio design. Genet Epidemiol 2002; 22: 1-11.

37 Shotelersuk V, Ittiwut C, Sirivan P, Angspatt A: Maternal 677CT/ 1298AC genotype of the MTHFR gene as a risk factor for cleft lip. J Med Genet 2003; 40: e64.

38 Franzoso G, Bous V, Azarenko V et al: The oncoprotein Bcl-3 can facilitate NK-kB-mediated transactivation by removing inhibiting p50 homodimers from select $\mathrm{kB}$ sites. EMBO $J$ 1993; 12: 3893-3901.

39 Amos C, Gasser D, Hecht JT: Nonsyndromic cleft lip with or without cleft palate: new BCL3 information. Am J Hum Genet 1996; 59: 743-744.

40 Wyszynski DF, Maestri N, McIntosh I et al: Evidence for an association between markers on chromosome $19 \mathrm{q}$ and nonsyndromic cleft lip with or without cleft palate in two groups of multiplex families. Hum Genet 1997; 99: 22-26.

41 Martinelli M, Scapoli L, Pezzetti F et al: Suggestive linkage between markers on chromosome 19q13.2 and nonsyndromic orofacial cleft malformation. Genomics 1998; 51: 177-181.

42 Fujita T, Nolan GP, Liou H-C, Scott ML, Baltimore D: The candidate proto-oncogene bcl-3 encodes a transcriptional coactivator that activates through NF-kB p50 homodimers. Genes Dev 1993; 7: 1354-1363.

43 Wong W, Eskes TKAB, Kuijpers-Jagtman AM et al: Nonsyndromic orofacial clefts: assocaition with maternal hyperhomocysteinemia. Teratology 60: 253-257.

44 Knott L, Hartridge T, Brown NL, Mansell JP, Sandy JR: Homocysteine oxidation and apoptosis: a potential cause of cleft palate. In Vitro Cell. Dev. Biol. Anim 2003; 39: 98-115. 